\title{
Do the radiological changes seen at mid term follow up of stemless shoulder prosthesis affect outcome?
}

\author{
Mohamed Moursy ${ }^{1 *}$, Milan Niks², Aditya S. Kadavkolan ${ }^{3}$ and Lars J. Lehmann ${ }^{4}$
}

\begin{abstract}
Background: The Eclipse ${ }^{\circledast}$ (Eclipse ${ }^{\circledast}$ is a trademark of Arthrex, Naples, Florida) stemless shoulder prosthesis offers the surgeon the advantage of bone stock preservation and at the same time avoids the drawbacks of a resurfacing arthroplasty. Previous studies have shown radiographic changes on serial follow up of the Eclipse prosthesis. This study attempts to assess the significance of these radiographic changes and effect of cuff related pathology on the mid-term outcome of the Eclipse prosthesis.

Methods: Between July 2005 and October 2008, 29 shoulders underwent shoulder arthroplasty with the Eclipse prosthesis; 23 shoulders, (seven women and 16 men) were available for the final follow up. The range of motion, Constant Score; age adjusted Constant Score, Subjective Shoulder Value and radiographs were assessed at serial follow-ups.
\end{abstract}

Results: Significant improvements were seen in the Constant Score $(78.9 \pm 20.1)$ compared to pre-operative score (32.9 \pm 5.2$)$; also forward elevation, abduction and external rotation improved to $142.9 \pm 36.6^{\circ}, 135.2 \pm 40.5^{\circ}$ and $49.8 \pm 21.9^{\circ}$ at 72 months $(p<0.001)$. Radiolucent lines and localised osteopenia, did not statistically impact on the clinical outcome. Partial tears of the supraspinatus and subscapularis had a negative impact on the Subjective Shoulder Value $(p<0.05)$ Partial or complete tears of the subscapularis led to worse Constant Score on follow up $(p<0.05)$.

Conclusions: The presence of radiolucent lines or localised osteopenia does not influence the mid term clinical outcome. Pre -operative partial supraspinatus tears or tears of the subscapularis lead to an inferior outcome.

Keywords: Shoulder arthroplasty, Shoulder arthritis, Stemless arthroplasty, Eclipse prosthesis, Total shoulder arthroplasty

\section{Background}

Modularity in current third and fourth generation prosthesis allows for restoration of shoulder biomechanics [1-3]. The last decade has seen an increase in the stemless implants so as to circumvent the complications associated with a stemmed prosthesis namely periprosthetic fractures and loosening. The average interval for loosening has been found to be $7.7 \pm 4$ years and for periprosthetic fractures the duration has been found to be $5.8 \pm 4.7$ years [4]. Intra operative perioperative fractures may occur due to forceful

\footnotetext{
* Correspondence: m.moursy@gmail.com

Lars J. Lehmann is a senior author.

'Department of Orthopedics and Traumatology, Paracelsus Medical

University, Salzburg, Austria

Full list of author information is available at the end of the article
}

manipulation or a mistake in introduction of the stem in the diaphysis [5]. In a meta-analysis 27 of 414 complications in shoulder arthroplasty were due to loosening of the stem [6] To overcome the loss of bone stock and the stem associated complications humeral resurfacing arthroplasty was introduced [7]. The resurfacing offers accurate offset, as there is no stem; however angulation is prone to major errors [8]. Good results with shoulder resurfacing have been recorded in cases of rheumatoid arthritis, glenohumeral arthritis, in malunited humeral shaft fractures and in cases where there is an implant occupying the humeral shaft canal; difficulties are however seen in proximal humeral malunions and in patients with advanced collapse of the humeral head $[5,9,10]$. Also the procedure is 
technically demanding, requiring a circumferential capsulotomy for the glenoid exposure and humeral head protection during the glenoid preparation $[7,9]$.

Stemless implants offer the advantages of both resurfacing as well as the conventional stemmed prosthesisa) accurate offset since there is no stem, b) correct head angulation and version c) easy extraction during revision [8] d) less compromise of bone stock and e) avoidance of diaphyseal stress shielding as more of the metaphyseal bone is loaded [11].

Previous studies have shown radiographic changes around the implant at sequential follow up, many of which were asymptomatic $[12,13]$.

Whereas rotator cuff disease limited to the supraspinatus with minimal or no retraction has not shown to affect the outcomes of anatomical total shoulder arthroplasty; worse outcomes are observed in individuals with fatty infiltration and degeneration of the infraspinatus and to a lesser extent the subscapularis [14]. Similar outcomes have been noted by Ianotti et.al who observed no significant effect of a repairable supraspinatus tear on the increase in American Shoulder Elbow Society scores for pain, function and patient satisfaction in individuals undergoing anatomical prosthetic replacement [15].

In the present study it was hypothesized that the radiographic changes were mainly due to bone adaptation / stress redistribution around the implant and would not influence the clinical outcome. As has been discussed previously, anatomic total shoulder arthroplasty in gives predictable outcomes in individuals with isolated supraspinatus tear; whether the same applies to a stemless shoulder arthroplasty has not been assessed. Hence one of the objectives of the current study was to evaluate the effect of rotator cuff tears on the clinical outcome of the stemless prosthesis.

\section{Methods}

Between July 2005 and October 2008, 29 shoulders underwent shoulder arthroplasty with the Eclipse prosthesis performed by the senior author.

The patients were assessed clinically pre-operatively with the Constant -Murley score (CS) and the range of motion of the shoulder was evaluated. The clinical assessment was done by MM \& MN; passive and active range of motion of the shoulder with regards to forward elevation, abduction and external rotation at side were assessed with a clinical goniometer. These measurements were again repeated at 6 weeks, 3 months, 6, 12, 24, 36 and 72 months. Additionally the age adjusted Constant Score and Subjective Shoulder Value (SSV) was used for measuring the outcome.

Radiographic evaluation was done with AP and axillary radiographs; radiolucencies and osteopenia were measured in three zones $a, b$ and $c$ around the implant base and coring screw as previously described by Habermeyer et.al in the Anteroposterior (AP) and axillary views of the shoulder [13] (Fig. 1). Stress shielding was assessed from tuberosity resorption, cortical thinning, and calcar osteolysis [16]. The radiographic observations were made by two observers trained and experienced in shoulder surgery MM \& MN as per the system devised by Habermeyer [13]. The final conclusion of the radiological changes were based on inter observer agreement.

Pre operatively the rotator cuff was evaluated with the help of a 3 Tesla MRI with standard sequences. We assessed the MRI for presence rotator cuff tear, presence of fatty infiltration and retraction. Rotator cuff tears involving the supraspinatus, infraspinatus or the subscapularis were graded as nil (0), partial tear (1) or complete tear (2). Fatty infiltration was graded absent $(1)(\leq 2$ Goutallier) or present ( $\geq 2$ Goutallier).

All the surgeries were performed under General Anaesthesia with the patient in the beach chair position. A deltopectoral approach from the coracoid extending inferior and laterally over the superior aspect of the axillary fold was used. The deltoid muscle was mobilized laterally and retracted. The lateral end of the subscapularis was identified and tag sutures with no. 5 fiberwire $^{\infty 1}$ were taken for later attachment of the muscle to the bone. A long head of biceps tenotomy was performed in all the cases. A capsular release till 6 'o clock position of the humerus was done and the head was dislocated anteriorly for resection. The arm was positioned at more than $90^{\circ}$ external rotation and $30^{\circ}$ extension and adduction for head resection.

The Eclipse prosthesis is an uncemented humeral head replacement prosthesis, which has a central coring screw for fixation to the humeral metaphysis. The implant is available in sequential sizes and progressive thickness to replicate the proximal humerus geometry. The coring screw is available in Small, Medium and Large. However there is no modularity between the humeral head and the screw. The cemented polythene glenoid component comes in two variants; a keeled and a pegged back both of which have reverse bars and fenestration to improve the fixation. The decision to implant the glenoid was based on the Walch classification [17]. Eccentric glenoids were implanted while A1 glenoids were left alone.

Following the removal of osteophytes the head was resected with a resection guide, the triunion size was determined and the metaphysis was drilled for the coring screw. The sterile and sized triunion was finally placed and impacted and the coring screw placed through the central hole following which the head was impacted. In shoulders that required the placement of the glenoid component, the glenoid preparation was done after the

\footnotetext{
${ }^{1}$ Fiberwire ${ }^{\bullet}$ is a trademark of Arthrex Inc. Naples, Florida
} 


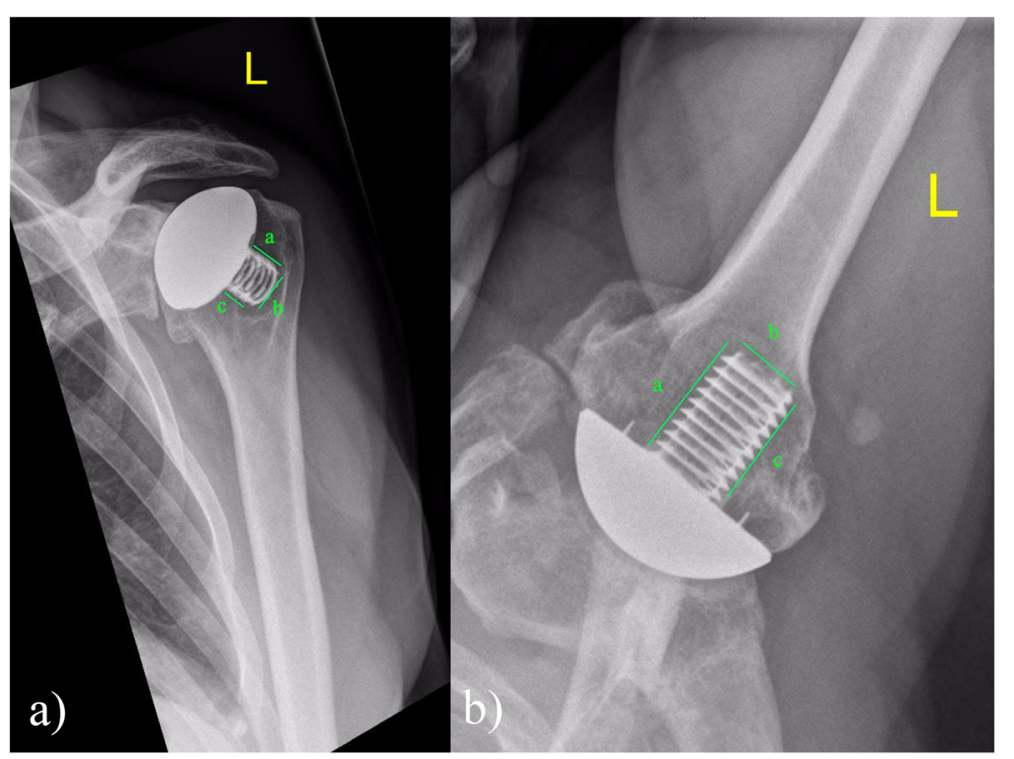

Fig. 1 Assessment of the radiolucencies around the humeral component as described by Habermeyer, a,b,c represent the zones around the prosthesis. a AP View, b Axillary view

humeral head osteotomy. For glenoid component preparation the humerus was subluxed posteriorly after tenotomy of the superior aspect of the tendon of the pectoralis major. It is paramount to achieve complete visualization of the glenoid to achieve optimal component placement. A guide was introduced at the centre of the glenoid followed by reaming and placement of a polythene glenoid component.

The arm was left postoperatively in a Gilchrist immobilization bandage for three weeks during which passive range of motion was permitted after which active range of motion exercises and active mobilization was initiated.

Data were entered in Microsoft Excel and analysed using Stata Version 15.1 (๔ StataCorp, College Station, Texas, USA). The mean and standard deviations for the linear variables were calculated. The means between two groups were compared using the t-test. The analysis of variance to assess the difference in means in more than two groups was use. The Pearson's correlation co-efficient was used to estimate the correlation between two linear variables; $p<0.05$ was considered to be statistically significant.

\section{Results}

No intra-operative complications were observed in any of the patients. subscapularis lengthening was performed in 17 patients. Two patients required a repair of the supraspinatus during the surgery. The mean operative time was $73 \pm 15.2 \mathrm{~min}$ and the blood loss was $215 \pm 29.2 \mathrm{ml}$.

Out of the 29 shoulders, 23 (seven women and 16 men) were available for the final follow up of which three were followed up through a self-assessment form. Only the individuals who had completed a minimum of 72 months were included in the study. Six patients were lost to follow up and not included in the study; one patient had developed bronchogenic carcinoma and had expired; one individual developed sepsis necessitating implant removal; four patients developed worsening of the cuff tear necessitating a conversion to a reverse prosthesis. Of the 23 patients included in the study patients 21 had undergone hemi replacement and 2 had undergone total shoulder replacement arthroplasty (Fig. 2). The aetiology was idiopathic osteoarthritis (63.2\%), congenital dysplasia (10.2\%), osteonecrosis (10.5\%), cuff arthropathy (5.3\%) and post- traumatic arthritis (10.5\%). One patient with bilateral shoulder dysplasia underwent a bilateral staged procedure for the same. The preoperative MRI demonstrated partial tear of the supraspinatus in 13 shoulders of which four had a fatty degeneration, partial tear of the infraspinatus in one shoulder, total rupture of the subscapularis in four and partial subscapularis tear in six shoulders. One patient had Nickel allergy and a gold-coated implant was used for the same.

Two patients required revision surgery, one in whom the glenoid base plate was changed from a metallic to polyethylene and the other patient had a periprosthetic fracture of the humerus.

Mean age at the time of surgery was $59.9 \pm 9.2 \mathrm{yrs}$; the mean duration of follow-up was $7.57 \pm 1.09$ yrs. The mean age adjusted Constant Score was $32.9 \pm 5.2$ preoperative that improved to $78.9 \pm 20.1$ at last follow up. The increase in the Constant Score was found to be 


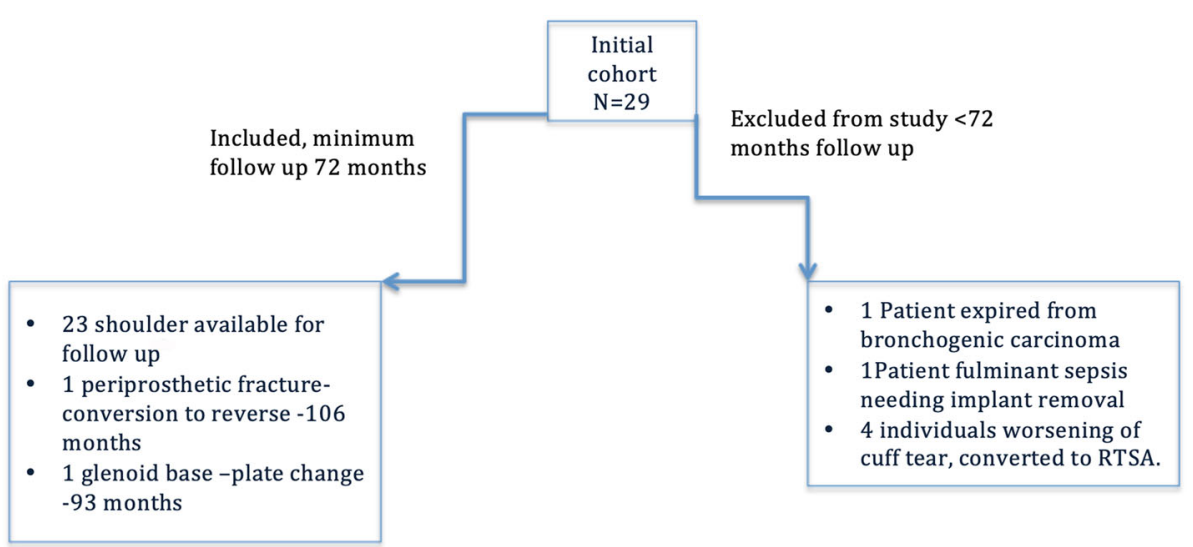

Fig. 2 Flowchart depicting the inclusion/exclusion criteria in the study

statically significant between the pre-operative values and at the last follow up $(p<0.0001)$. The post op Subjective Shoulder Value (SSV) was measured to be $70.5 \pm 21.1$.

The change in the range of motion of the shoulder has been described in Table 1. There was a significant increase in the range of motion with respect to flexion, extension and external rotation between the pre-operative values and at the last follow up ( $\mathrm{p}<0.0001)$.

Serial AP and axillary lateral radiographs were done at follow up. The mean duration of the radiological follow up was $88.1 \pm 21.4$ months. The system developed by Habermyer was used to classify the radiolucent lines $<2$ $\mathrm{mm}$ [13] (Fig. 1). Radiolucent lines $>2 \mathrm{~mm}$ were observed in three shoulders. The presence of radiolucent lines $<2$ $\mathrm{mm}$ did not influence the clinical outcome with regards to the post operative age adjusted CS, shoulder range of active or passive movement or the SSV (Table 2).

Progressive cranial migration of the humeral head, with a decrease in acromio-humeral interval from $9.05 \pm$ $3.6 \mathrm{~mm}$ to $5.01 \pm 2.3 \mathrm{~mm}$ was observed at final follow up. Decrease in acromio-humeral interval correlated with poorer external rotation at follow up (Coefficient of correlation $=1$ ).

Secondary glenoid wear was seen in 10 shoulders, secondary osteophytes were seen in 7 shoulders. Radiolucent glenoid lines were not seen in any shoulders. The glenoid wear and secondary glenoid osteophytes had no significant bearing on the clinical outcome at the last follow up in terms of the measured parameters, age adjusted CS, SSV, post operative shoulder range both active and passive (Table 3).

There were two variations in the pattern of stress shielding observed: of the 13 shoulders with centred prosthesis 11 had evidence of bone on growth on the calcar (Fig. 3); three out of six patients with a decentred prosthesis showed evidence of stress shielding around the coring screw (Fig. 4). Clinical instability was not observed in any of the shoulders. On the glenoid aspect sclerosis was seen in 13 patients who had undergone hemi replacement.

The statistical assessment revealed that the presence of pre-operative partial supraspinatus tear led to inferior SSV $(p=0.01)$. Complete / partial tears of the subscapularis similarly had a negative impact on the outcome with worse SSV $(p=0.04)$, CS $(0.01)$ and post- operative increase in external rotation $(p<0.5)$. However fatty infiltration of the supraspinatus, infraspinatus partial tears did not influence on the postoperative SSV, the age adjusted CS or the postoperative shoulder active /passive range (Table 4).

Localised osteopenia was observed in the zones $a, b, c$ in the anteroposterior and axillary radiographs. The presence of localised osteopenia did not influence the clinical outcome with regards to the measured clinical

Table 1 Clinical assessment of the outcome

\begin{tabular}{|c|c|c|c|c|c|c|c|c|}
\hline \multirow[t]{2}{*}{ Duration } & \multicolumn{2}{|l|}{ Flexion } & \multicolumn{2}{|l|}{ Abduction } & \multicolumn{2}{|c|}{ External rotation } & \multirow[t]{2}{*}{ CS } & \multirow{2}{*}{$\begin{array}{l}\text { Age } \\
\text { adjusted } \\
\text { CS }\end{array}$} \\
\hline & Active & Passive & Active & Passive & Active & Passive & & \\
\hline Pre-op & $71.4 \pm 15.9$ & $90.9 \pm 22.5$ & $68.1 \pm 13.2$ & $86.6 \pm 20$ & $27.6 \pm 11.9$ & $33.1 \pm 9.1$ & $\begin{array}{l}32.9 \\
\pm 5.2\end{array}$ & $33.76 \pm 5.1$ \\
\hline $72 \mathrm{mo}$ & $142.9 \pm 36.6$ & $160.5 \pm 32.3$ & $135.2 \pm 40.5$ & $148.5 \pm 38.9$ & $49.8 \pm 21.9$ & $51.6 \pm 14.8$ & $\begin{array}{r}78.9 \\
\pm 20.1\end{array}$ & $83 \pm 15.9$ \\
\hline
\end{tabular}


Table 2 Influence of radiological parameters on clinical outcome

\begin{tabular}{|c|c|c|c|c|c|c|c|c|}
\hline \multirow[t]{2}{*}{ Parameter } & \multicolumn{2}{|l|}{$\mathrm{n}$} & \multicolumn{2}{|l|}{$\mathrm{CS}$} & \multirow{2}{*}{$\begin{array}{l}p \\
\text { value }\end{array}$} & \multicolumn{2}{|l|}{ SSV } & \multirow{2}{*}{$\begin{array}{l}p \\
\text { value }\end{array}$} \\
\hline & Absent & Present & Absent & Present & & Present & Absent & \\
\hline ap-a & 19 & 3 & $43.7 \pm 21.5$ & $49.0 \pm 21.6$ & 0.5 & $90.0 \pm 10$ & $68.7 \pm 21$ & 0.1 \\
\hline$a p-b$ & 20 & 2 & $46.1 \pm 21.6$ & $45.0 \pm 21.2$ & 0.9 & $65.0 \pm 49.5$ & $73.2 \pm 18.9$ & 0.61 \\
\hline ap-c & 19 & 3 & $46.8 \pm 21.2$ & 30.0 & 0 & $66.6 \pm 32.1$ & $73.4 \pm 20$ & 0.61 \\
\hline$a x-a$ & 20 & 2 & $46.6 \pm 22.1$ & $43.2 \pm 17.7$ & 0.78 & $85 \pm 7$ & $71.2 \pm 21.7$ & 0.39 \\
\hline$a x-b$ & 20 & 2 & $45.5 \pm 22$ & $49.0 \pm 16.5$ & 0.79 & $95 \pm 7$ & $70.2 \pm 20.8$ & 0.11 \\
\hline$a x-c$ & 18 & 4 & $43.4 \pm 22.6$ & $54.2 \pm 13.7$ & 0.3 & $75.0 \pm 31$ & $71.9 \pm 19.4$ & 0.8 \\
\hline AP-A & 12 & 10 & $43.2 \pm 21.4$ & $62.6 \pm 4.9$ & 0.1 & $74.5 \pm 23.1$ & $70.8 \pm 20.2$ & 0.69 \\
\hline AP-B & 20 & 2 & $45.7 \pm 21.3$ & $48.0 \pm 25.4$ & 0.8 & $60.0 \pm 42.4$ & $73.7 \pm 19.5$ & 0.39 \\
\hline AP-C & 21 & 1 & $45.22 \pm 21.8$ & $50.6 \pm 18.3$ & 0.6 & 30.0 & $74.5 \pm 19.36$ & - \\
\hline$A X-A$ & 18 & 4 & $44.4 \pm 21.5$ & $61 \pm 5.6$ & 0.3 & $70.0 \pm 28.2$ & $73.0 \pm 20.2$ & 0.8 \\
\hline$A X-B$ & 19 & 3 & $44.3 \pm 21.4$ & $61.5 \pm 6.3$ & 0.2 & $70.0 \pm 34.6$ & $72.8 \pm 19.6$ & 0.8 \\
\hline$A X-C$ & 17 & 5 & $44 \pm 21.8$ & $54.5 \pm 16.8$ & 0.3 & $75.0 \pm 26.9$ & $71.7 \pm 20.0$ & 0.7 \\
\hline
\end{tabular}

ap $a, b, c$ represent zones for measurement on the AP radiograph and ax a,b,c represent zones on the axillary radiograph

Small caps indicate bone density loss, Capitals indicate radiolucent lines

$n$ number

CS Constant score

SSV Subjective shoulder value

parameters (Table 2). Similar results were seen in other studies in this regard (Table 5).

\section{Discussion}

In the current study, presence of radiolucent lines $<2$ $\mathrm{mm}$ did not influence the clinical outcome with regards to the post operative age adjusted CS, shoulder range of active or passive movement or the SSV. Two patterns of stress shielding were observed, in centred prosthesis it was observed around the calcar in 11/13 shoulders while in decentred prosthesis it was seen around the coring screw in 3 out of 6 shoulders. Decrease in acromiohumeral distance on the radiographs led to a worsening outcome. Presence of pre-operative partial supraspinatus tear was a predictor for a poorer outcome with inferior SSV $(p=0.01)$. Complete / partial tears of the subscapularis similarly had a negative impact on the outcome with worse SSV $(p=0.04)$, CS (0.01) and post- operative increase in external rotation $(p<0.5)$.

Restoration of the proximal humeral anatomy involves accurate reproduction of the offset, version, the angulation of the head, the neck length and lastly the head diameter. The stemless Eclipse ${ }^{\circ}$ prosthesis allows an accurate reproduction of these parameters; lack of a stem ensures replication of the offset, the neck cut allows accurate restoration of the angulation, the retroversion and the neck length [8].

The results of the current study are better compared to other studies done to assess the outcome of stemmed shoulder arthroplasty in terms of the Constant Score and the shoulder range of motion [4, 18-21] (Table 6) $[4,18-23]$. However it must be mentioned that the duration of the follow up in our study was minimum 72 months, which was less than some of these studies. The clinical results of the stemless prosthesis are superior compared to the Copeland resurfacing. Additionally due to head resection the complications associated with the glenoid exposure in surface replacement are avoided [10] (Table 7) [5, 9, 10, 24-26].

The results of the current study are similar in terms of the post -operative Constant Score and range of motion when compared to the other studies of stemless implants $[5,13,27,28]$ (Table 7).

Churchill et al. investigated the outcome of Simpliciti stemless prosthesis (Wright medical) in 157 patients with glenohumeral osteoarthritis. Of 157 patients 149 patients were available with a minimal follow up of 2 years. Range of motion increased from $103^{\circ}$ to $147^{\circ}$ and external rotation from $31^{\circ}$ to $57^{\circ}$. The authors described a subjective method of assessing the metaphyseal bone stock by compressing it with operating surgeons thumb; if there was no indentation the bone stock was considered adequate for implantation else a conventional prosthesis was used. The authors did not observe any component loosening, proximal migration of the humeral head [29].

Habermeyer et al. in a study of 78 patients with a minimal follow up of 72 months compared the results of Eclipse prosthesis in a osteoarthritis group $(n=39)$ to that of post traumatic arthritis group $(n=26)$. Both populations showed a significant increase in the CS and active range of motion post surgery. The osteoarthritis group had better increase in abduction compared to the posttraumatic arthritis group. The results of hemiarthroplasty 


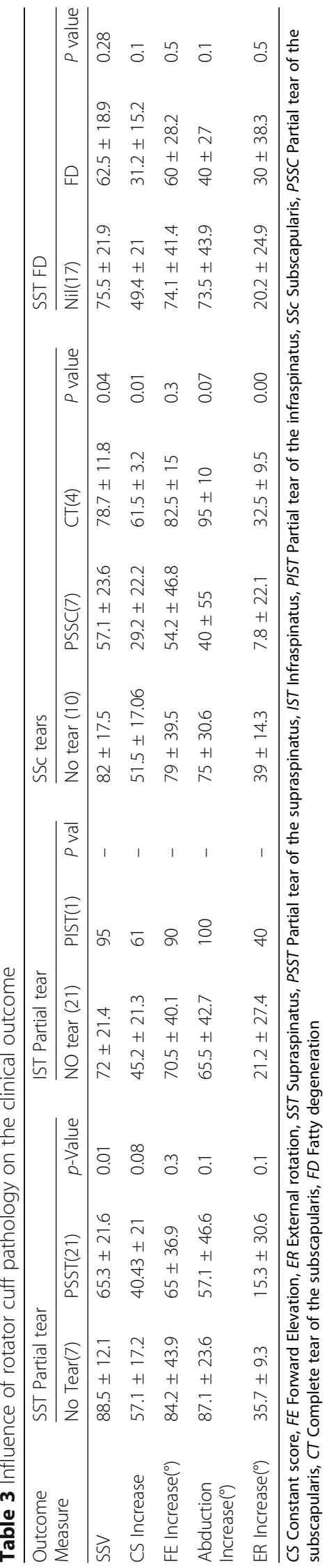




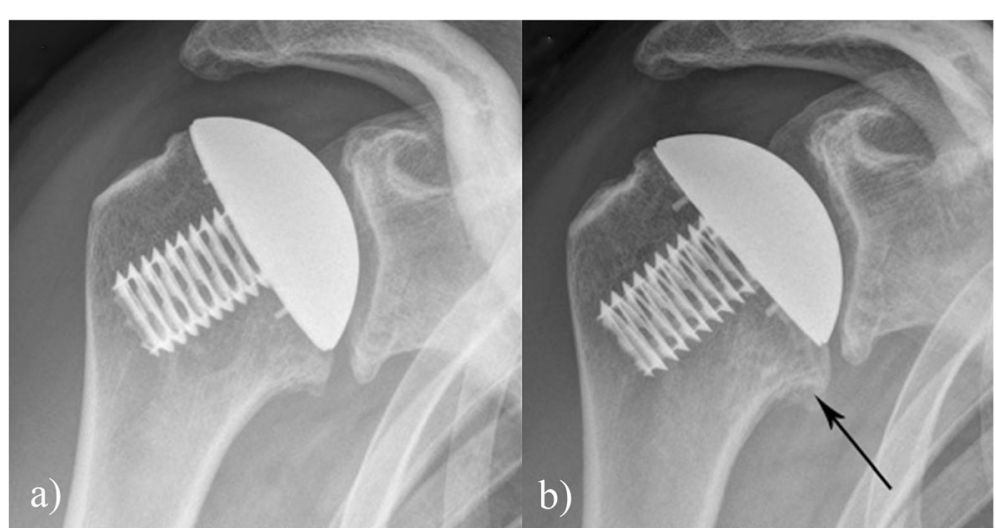

Fig. 3 a Post operative image post surgery, $\mathbf{b}$ radiograph at eight years showing stress shielding around the calcar as indicated by the arrow

compared to total shoulder arthroplasty were similar in both groups [13]. In our study the sample size of patients belonging to each aetiology group was less to derive a statistically significant correlation.

Uschok et.al in a randomised trial compared the outcomes of the Eclipse prosthesis to a conventional stemmed prosthesis and obtained similar results in terms of post operative Constant Score and improvement in range of movement over a period of the study of five years; they also observed that the positive results were maintained during the follow up. Also it was noted that the bone density was lowered in the calcar region (Zone c AP radiograph) in more individuals undergoing the conventional stemmed prosthesis compared to the Eclipse prosthesis [30].

Radiolucent lines were observed in zones $a, b, c$ as described by Habermyer in the AP and axillary radiographs (Table 2, Fig. 1). Similarly localised osteopenia was observed on examination of the follow up radiographs; the results of which are summed up in Table 2 and comparison to other studies in this regard in Table 5. Golkhe et al. in a cadaveric study has suggested that radiolucent lines around stemless prosthesis may be a radiation artefact due to radiation scatter rather than true bone loss or stress shielding [31].

Stress shielding was another phenomenon observed during our study. The adaptation of the host bone in response to a prosthesis inserted in the medullary cavity is called stress shielding as per Wolff's law [32]. Stress shielding can manifest as tuberosity resorption, cortical thinning, calcar osteolysis and occurs because of sharing of load between the prosthesis and bone; both material with different Young's moduli [16]. The degree of stress shielding and the location varies depending on the prosthesis size and design [16]. Previous studies have indicated stress shielding around humeral resurfacing implants; especially around the rim and the core [33]. External stress shielding in form of calcar sclerosis was seen in the shoulders with a centred implant, whereas the internal stress shielding was seen in de-centred implant. Lesser bone density loss is seen in stemless prosthesis compared to stemmed prosthesis [30].

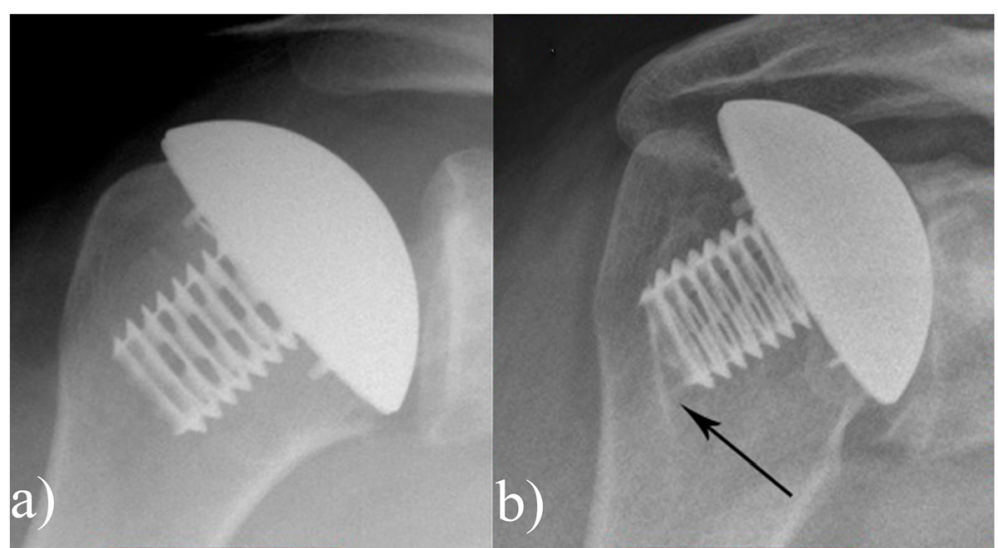

Fig. 4 a Post operative image post surgery, b radiograph at six years showing stress shielding around the coring screw indicated by the arrow 


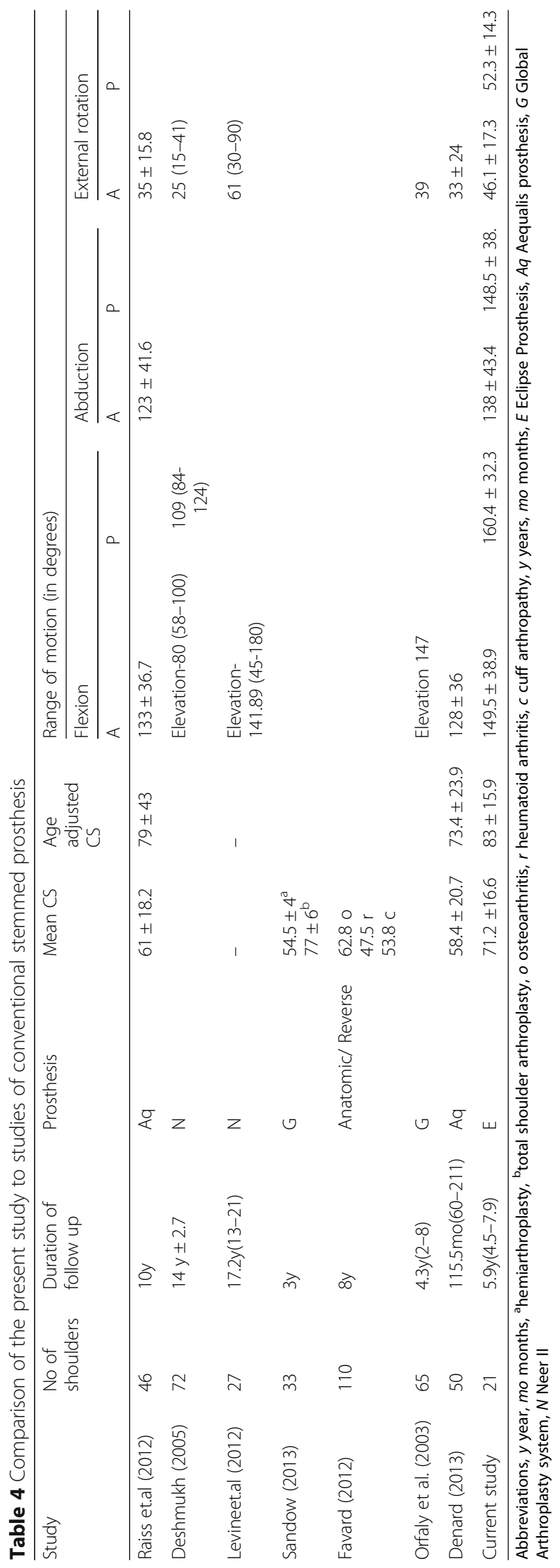




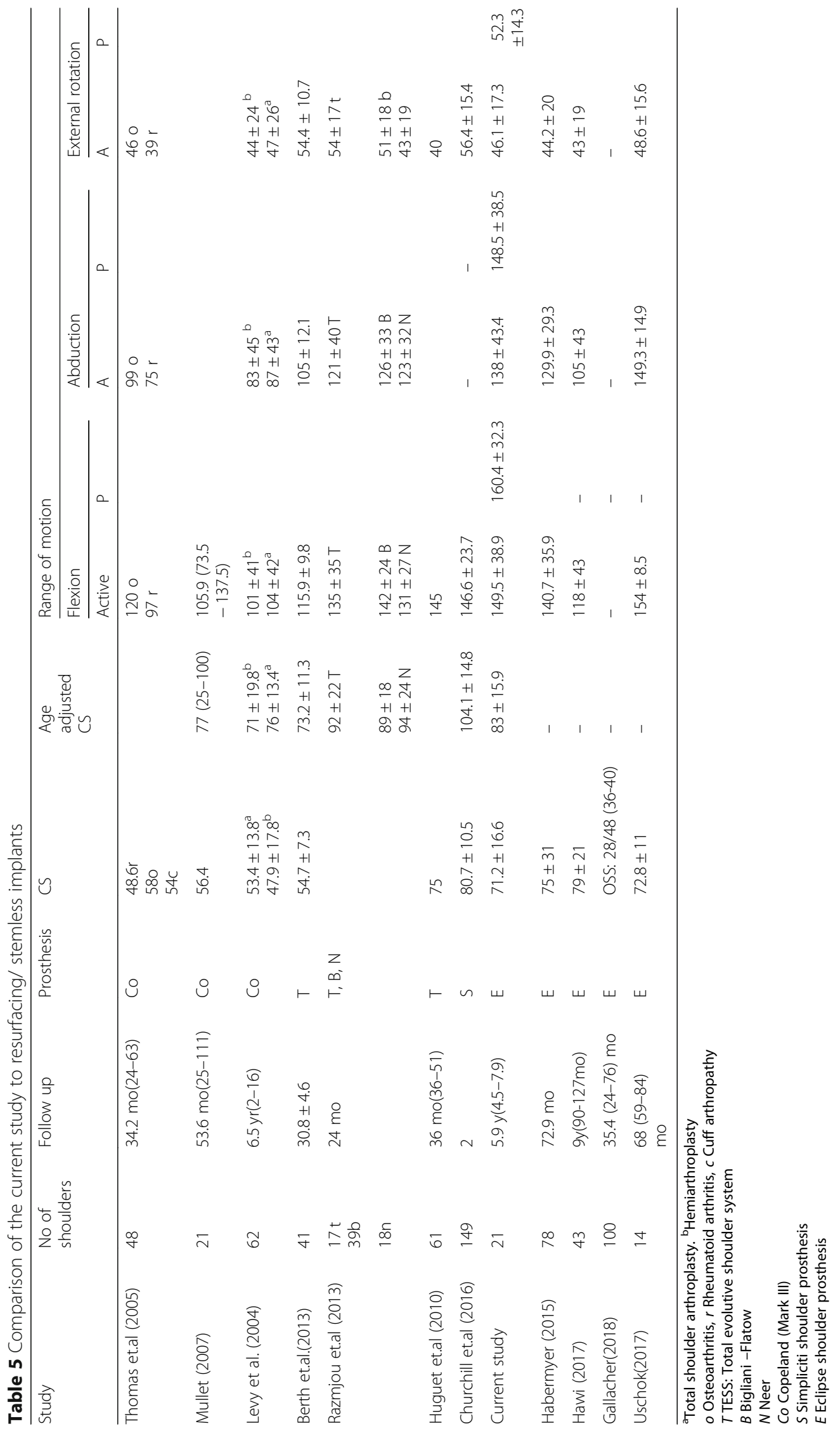


Moursy et al. BMC Musculoskeletal Disorders

(2019) 20:490

Page 10 of 12

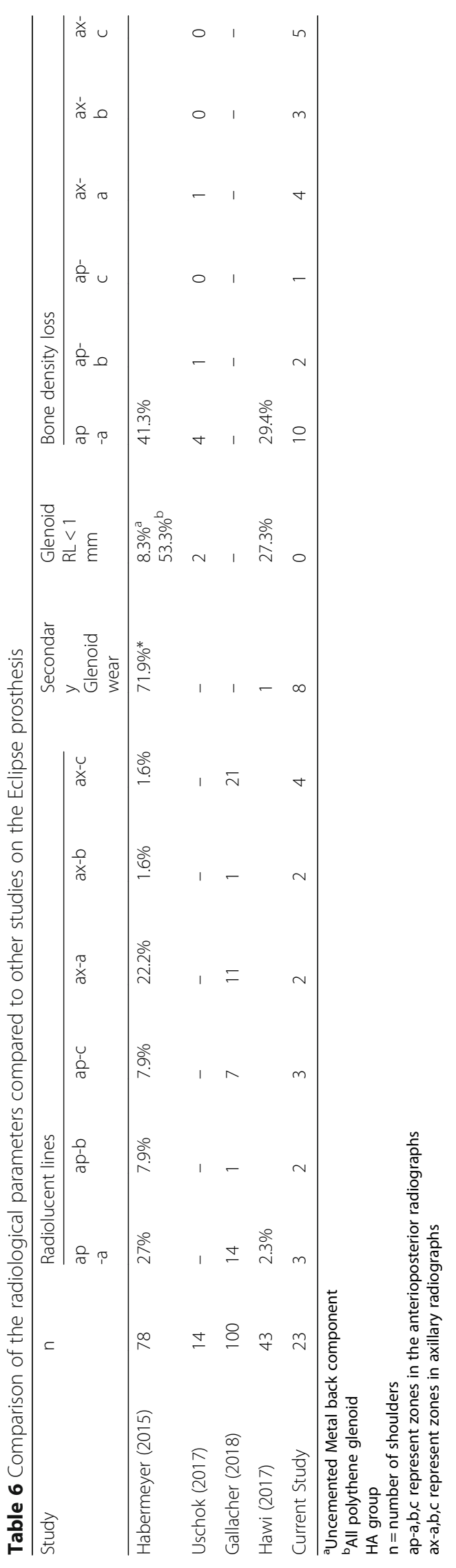


Table 7 Radiological changes on the glenoid and effect on clinical outcome

\begin{tabular}{|c|c|c|c|c|c|c|}
\hline \multirow[t]{2}{*}{ Variable } & \multicolumn{2}{|c|}{ Secondary Osteophytes } & \multirow{2}{*}{$\begin{array}{l}P \\
\text { value }\end{array}$} & \multicolumn{2}{|c|}{ Secondary Glenoid wear } & \multirow{2}{*}{$\begin{array}{l}P_{-} \\
\text {Value }\end{array}$} \\
\hline & Absent & Present & & Absent & Present & \\
\hline SSV & $70.3 \pm 22.7$ & $77.4 \pm 17.9$ & 0.49 & $72.1 \pm 20$ & $73.1 \pm 24.3$ & 0.9 \\
\hline CS increase & $44.3 \pm 21.7$ & $50.1 \pm 20.4$ & 0.57 & $47 \pm 20.3$ & $44.3 \pm 23.4$ & 0.7 \\
\hline
\end{tabular}

SSV Subjective shoulder value, CS Constant Score

Edwards et.al in a multi centre study observed that supraspinatus tear in individuals undergoing shoulder arthroplasty had no influence on the post-op constant score or patient satisfaction. Repairing the supraspinatus tear had no influence on the clinical outcome other than an improvement in post operative external rotation; individuals with supraspinatus tears had lesser strength than individuals without the tear. Fatty infiltration of the infraspinatus, subscapularis had more negative impact on the outcome [14]. In contrast in our study we observed worse postoperative SSV in individuals having partial supraspinatus tear as well as tears of the subscapularis. Fatty infiltration of the supraspinatus had no influence on the final result.

Despite the good clinical outcomes and clinicradiological outcomes similar to other studies if the stemless prosthesis, this study has a few drawbacks. The patient cohort was small to assess the effect of each of the pathologies leading to glenohumeral arthritis on the outcome. A hemiarthroplasty was done in a majority of the cases, however our main aim of the study was to assess the radiolucent lines that have been observed on the humeral side following a stemless shoulder arthroplasty. Additionally we lacked a control cohort to compare the clinical and radiological outcomes, as it was a retrospective study.

\section{Conclusions}

An important message from the study is that localised osteopenia and radiolucent lines are common after stemless prosthesis implantation, and these are not predictors of worse clinical outcome in mid term; however it need to be seen in the longer run if these radiological findings assume any clinical significance. In presence of rotator cuff disease, stemless shoulder prosthesis needs to be approached with caution as inferior results are seen in presence of supraspinatus tears and subscapularis tears.

\section{Supplementary information}

Supplementary information accompanies this paper at https://doi.org/10 1186/s12891-019-2870-z.

Additional file 1.

Additional file 2.

Additional file 3.

Additional file 4.

\section{Abbreviations}

CS: Constant score; L: Large; M: Medium; S: Small; SSV: Subjective shoulder value

\section{Acknowledgements \\ Not applicable}

\section{Authors' contributions}

MM: Data collection, patient follow up and Manuscript preparation. MN: Data collection, patient follow up. ASK: Data analysis and manuscript preparation. LJL: Senior Author, operating surgeon, concept and design of the study. All authors have read and approved the final manuscript.

\section{Funding}

No funding obtained for the study.

\section{Availability of data and materials}

All data generated or analysed during this study are included in this published article. The raw data is submitted as Additional files 1, 2, 3 and 4.

\section{Ethics approval and consent to participate}

Written informed consent was obtained from all individual participants to be included in the study. The ethics committee approval was obtained (Ref no: 2016-55 N-MA).

Ethics Committee:

Medicine Faculty Mannheim,

Medical ethics committee ॥

Prof Dr. Med Jens P Stribel

Centre for medical research

House 42, Building 3

Mannheim Medical University, Theodore -Kutzer-Ufer 1-3

Mannheim, Germany-68,167

\section{Consent for publication}

Not applicable

\section{Competing interests}

The authors declare that they have no competing interests.

\section{Author details}

${ }^{1}$ Department of Orthopedics and Traumatology, Paracelsus Medical University, Salzburg, Austria. ${ }^{2}$ Dept. of Traumatology, Emergency hospital Graz, Graz, Austria. ${ }^{3}$ Consultant Arthroscopy, Sports Medicine \& Shoulder surgery, Dr. LH Hiranandani Hospital, Powai, Mumbai 400076, India. ${ }^{4}$ Orthopedic \& Trauma Centre, Medical Faculty Mannheim, Heidelberg University Mannheim, Mannheim, Germany.

Received: 24 March 2019 Accepted: 9 October 2019

Published online: 27 October 2019

\section{References}

1. Wirth MA, Ondrla J, Southworth C, Kaar K, Anderson BC, Rockwood CA. Replicating proximal humeral articular geometry with a third-generation implant: a radiographic study in cadaveric shoulders. J Shoulder Elbow Surg. 2007;16(3):S111-S6.

2. Norris TR, lannotti JP. Functional outcome after shoulder arthroplasty for primary osteoarthritis: a multicenter study. J Shoulder Elbow Surg. 2002; 11(2):130-5.

3. Pearl ML, Kurutz S. Geometric Analysis of Commonly Used Prosthetic Systems for Proximal Humeral Replacement*. J Bone Joint Surg. 1999:81(5): 660-71. 
4. Deshmukh AV, Koris M, Zurakowski D, Thornhill TS. Total shoulder arthroplasty: long-term survivorship, functional outcome, and quality of life. J Shoulder Elbow Surg. 2005;14(5):471-9.

5. Huguet D, DeClercq G, Rio B, Teissier J, Zipoli B, Group T. Results of a new stemless shoulder prosthesis: Radiologic proof of maintained fixation and stability after a minimum of three years' follow-up. J Shoulder Elbow Surg. 2010;19(6):847-52

6. Bohsali Kl, Wirth MA, Rockwood CA. Complications of total shoulder arthroplasty. J Bone Joint Surg. 2006;88(10):2279-92.

7. Copeland S. Cementless total shoulder replacement. Surgery of the shoulder St Louis: Mosby-Year Book. 1990;1990:289-93.

8. Bunker T. Stemless shoulder replacement, the best of both worlds: a personal view. Shoulder Elbow. 2011;3(2):64-73.

9. Mullett H, Levy O, Raj D, Even T, Abraham R, Copeland SA. Copeland surface replacement of the shoulder results of an hydroxyapatite-coated cementless implant in patients over 80 years of age. J Bone Joint Surg British Volume. 2007;89(11):1466-9.

10. Levy O, Funk L, Sforza G, Copeland SA. Copeland surface replacement arthroplasty of the shoulder in rheumatoid arthritis. J Bone Joint Surg. 2004; 86(3):512-8.

11. Harmer L, Throckmorton T, Sperling JW. Total shoulder arthroplasty: are the humeral components getting shorter? Curr Rev Musculoskelet Med. 2016; 9(1):17-22.

12. Hawi N, Tauber M, Messina MJ, Habermeyer P, Martetschläger F. Anatomic stemless shoulder arthroplasty and related outcomes: a systematic review. BMC Musculoskelet Disord. 2016;17(1):376.

13. Habermeyer $P$, Lichtenberg $S$, Tauber M, Magosch P. Midterm results of stemless shoulder arthroplasty: a prospective study. J Shoulder Elbow Surg. 2015;24(9):1463-72.

14. Edwards TB, Boulahia A, Kempf J-F, Boileau P, Nemoz C, Walch G. The Influence of Rotator Cuff Disease on the Results of Shoulder Arthroplasty for Primary Osteoarthritis: Results of a Multicenter Study. Jbjs. 2002:84(12):2240-8.

15. lannotti JP, Norris TR. Influence of Preoperative Factors on Outcome of Shoulder Arthroplasty for Glenohumeral Osteoarthritis. Jbjs. 2003;85(2):251-8.

16. Denard PJ, Raiss P, Gobezie R, Edwards TB, Lederman E. Stress shielding of the humerus in press-fit anatomic shoulder arthroplasty: review and recommendations for evaluation. J Shoulder Elbow Surg. 2018;27(6):1139-47.

17. Walch G, Badet R, Boulahia A, Khoury A. Morphologic study of the glenoid in primary glenohumeral osteoarthritis. J Arthroplasty. 1999;14(6):756-60.

18. Raiss P, Schmitt M, Bruckner T, Kasten P, Pape G, Loew M, et al. Results of cemented total shoulder replacement with a minimum follow-up of ten years. J Bone Joint Surg. 2012;94(23):e171.

19. Levine WN, Fischer CR, Nguyen D, Flatow EL, Ahmad CS, Bigliani LU. Longterm follow-up of shoulder hemiarthroplasty for glenohumeral osteoarthritis. J Bone Joint Surg. 2012;94(22):e164.

20. Orfaly RM, Rockwood CA, Esenyel CZ, Wirth MA. A prospective functional outcome study of shoulder arthroplasty for osteoarthritis with an intact rotator cuff. J Shoulder Elbow Surg. 2003;12(3):214-21.

21. Sandow MJ, David H, Bentall SJ. Hemiarthroplasty vs total shoulder replacement for rotator cuff intact osteoarthritis: how do they fare after a decade? J Shoulder Elbow Surg. 2013;22(7):877-85.

22. Favard L, Katz D, Colmar M, Benkalfate T, Thomazeau H, Emily S. Total shoulder arthroplasty-Arthroplasty for glenohumeral arthropathies: Results and complications after a minimum follow-up of 8 years according to the type of arthroplasty and etiology. Orthop Traumatol Surg Res. 2012;98(4):S41-S7.

23. Denard PJ, Raiss P, Sowa B, Walch G. Mid-to long-term follow-up of total shoulder arthroplasty using a keeled glenoid in young adults with primary glenohumeral arthritis. J Shoulder Elbow Surg. 2013;22(7):894-900.

24. Thomas SR, Wilson AJ, Chambler A, Harding I, Thomas M. Outcome of Copeland surface replacement shoulder arthroplasty. J Shoulder Elbow Surg. 2005;14(5):485-91.

25. Razmjou H, Holtby R, Christakis M, Axelrod T, Richards R. Impact of prosthetic design on clinical and radiologic outcomes of total shoulder arthroplasty: a prospective study. J Shoulder Elbow Surg. 2013;22(2):206-14.

26. Berth A, Pap G. Stemless shoulder prosthesis versus conventional anatomic shoulder prosthesis in patients with osteoarthritis. J Orthop Traumatol. 2013; 14(1):31-7.

27. Gallacher S, Williams HLM, King A, Kitson J, Smith CD, Thomas WJ. Clinical and radiologic outcomes following total shoulder arthroplasty using Arthrex Eclipse stemless humeral component with minimum 2 years' follow-up. J Shoulder Elbow Surg. 2018;27(12):2191-7.
28. Kadum B, Mafi N, Norberg S, Sayed-Noor AS. Results of the Total Evolutive Shoulder System (TESS ${ }^{\circ}$ ): a single-centre study of 56 consecutive patients. Arch Orthop Trauma Surg. 2011;131(12):1623-9.

29. Churchill RS, Chuinard C, Wiater JM, Friedman R, Freehill M, Jacobson S, et al. Clinical and Radiographic Outcomes of the Simpliciti Canal-Sparing Shoulder Arthroplasty System: A Prospective Two-Year Multicenter Study. J Bone Joint Surg Am Vol. 2016;98(7):552-60.

30. Uschok S, Magosch P, Moe M, Lichtenberg S, Habermeyer P. Is the stemless humeral head replacement clinically and radiographically a secure equivalent to standard stem humeral head replacement in the long-term follow-up? A prospective randomized trial. J Shoulder Elbow Surg. 2017; 26(2):225-32.

31. Hudek R, Werner B, Abdelkawi AF, Schmitt R, Gohlke F. Radiolucency in stemless shoulder arthroplasty is associated with an imaging phenomenons. J Orthop Res. 2016.

32. Frost HM. Wolff's Law and bone's structural adaptations to mechanical usage: an overview for clinicians. Angle Orthodontist. 1994;64(3):175-88.

33. Schmidutz F, Agarwal Y, Müller PE, Gueorguiev B, Richards RG, Sprecher CM. Stress-shielding induced bone remodeling in cementless shoulder resurfacing arthroplasty: a finite element analysis and in vivo results. J Biomech. 2014;47(14):3509-16.

\section{Publisher's Note}

Springer Nature remains neutral with regard to jurisdictional claims in published maps and institutional affiliations.
Ready to submit your research? Choose BMC and benefit from:

- fast, convenient online submission

- thorough peer review by experienced researchers in your field

- rapid publication on acceptance

- support for research data, including large and complex data types

- gold Open Access which fosters wider collaboration and increased citations

- maximum visibility for your research: over $100 \mathrm{M}$ website views per year

At BMC, research is always in progress.

Learn more biomedcentral.com/submissions 